\title{
Targeting Insulin-Like Growth Factor Binding Protein-3 Signaling in Triple-Negative Breast Cancer
}

\author{
Kamila A. Marzec, Robert C. Baxter, and Janet L. Martin \\ Hormones and Cancer Division, Kolling Institute of Medical Research, Royal North Shore Hospital, University of Sydney, \\ St Leonards, NSW 2065, Australia \\ Correspondence should be addressed to Janet L. Martin; janet.martin@sydney.edu.au
}

Received 20 July 2014; Accepted 29 September 2014

Academic Editor: Eileen M. McGowan

Copyright (C) 2015 Kamila A. Marzec et al. This is an open access article distributed under the Creative Commons Attribution License, which permits unrestricted use, distribution, and reproduction in any medium, provided the original work is properly cited.

\begin{abstract}
Insulin-like growth factor binding protein-3 (IGFBP-3) is a key regulatory molecule of the IGF axis and can function in a tissuespecific way as both a tumor suppressor and promoter. Triple-negative breast cancer (TNBC) has high tumor expression of IGFBP-3 associated with markers of poor prognosis and, although accounting for $15-20 \%$ of all breast cancers, is responsible for disproportionate rates of morbidity and mortality. Because they lack estrogen and progesterone receptors and overexpression of HER2, TNBC are resistant to treatments that target these molecules, making the development of new therapies an important goal. In addition to frequent high expression of IGFBP-3, these tumors also express EGFR highly, but targeting EGFR signaling alone in TNBC has been of little success. Identification of a functional growth-stimulatory interaction between EGFR and IGFBP-3 signaling prompted investigation into cotargeting these pathways as a novel therapy for TNBC. This involves inhibition of both EGFR kinase activity and a mediator of IGFBP-3's stimulatory bioactivity, sphingosine kinase-1 (SphK1), and has shown promise in a preclinical setting. Functional interaction between EGFR and IGFBP-3 may also promote chemoresistance in TNBC, and delineating the mechanisms involved may identify additional targets for development of therapies in cancers that express both IGFBP-3 and EGFR.
\end{abstract}

\section{An Introduction to the Insulin-Like Growth Factor Binding Proteins in Cancer}

The insulin-like growth factor (IGF) system is fundamental to normal growth and development, and by virtue of their potent proliferative and antiapoptotic effects, the polypeptide hormones IGF-I and IGF-II have also been shown to play an important role in tumorigenesis. The IGF binding proteins (IGFBPs) are key regulatory molecules of the IGF system, and aberrations in their expression or function have been associated with a range of cancers [1]. The IGFBP family comprises six IGFBPs (IGFBP-1 to IGFBP-6) that bind the IGFs with high affinity. They vary in length, ranging from 216 amino acids to 289 amino acids [2], and each consists of three regions: the highly conserved N-terminal and Cterminal domains which contain binding sites for the IGFs and the variable central or linker domain, which is also the region most commonly subject to posttranslational modification such as glycosylation, phosphorylation, and limited proteolysis and probably contributes to differences in IGFBP function [2].

The IGFBPs were first identified for their function as serum proteins that bind IGF-I and IGF-II, thereby extending the circulating half-life of IGFs from minutes to hours, regulating the hypoglycaemic potential of IGF-I and IGF-II, and controlling extravasation of the growth factors to target tissues [1]. IGFBPs also act in the pericellular environment to regulate IGF/IGF-receptor interaction, because the affinity of the IGFs for IGFBPs is similar to that for the IGF and insulin receptors [3]. This is important in the context of cancer, because IGF activation of these receptors elicits mitogenic and survival signals that promote tumor growth.

IGFBP-3 is responsible for carrying the vast majority of IGFs in the blood and is the most abundant circulating IGFBP. In this environment its role is clear: together with the acid-labile subunit (ALS), it stabilizes IGF-I and IGF-II in ternary complexes that have very slow dissociation rates and therefore long circulating half-lives $[4,5]$. Release of 
bioavailable IGFs from these complexes is generally thought to result from limited proteolytic cleavage of IGFBP-3, which reduces its binding affinity for IGFs [6-8].

IGFBP-3 is expressed by most tissues of the body and as an antagonist of IGF binding to the signal-transducing type 1 IGF receptor (IGF1R), it blocks the proliferative and cellsurvival effects elicited by its activation [3]. Consistent with this, loss of IGFBP-3 expression and consequent derepression of IGF1R signaling have been suggested to account for acquired resistance to the EGFR tyrosine kinase inhibitor gefitinib [9]. In vitro studies in breast cancer cells have also indicated that the efficacy of some anticancer agents, including retinoic acid, antiestrogens, and tumor necrosis factor-alpha (TNF $\alpha)$, is in part mediated by IGFBP-3 [1013]. Not all of these effects depend solely on inhibition of IGF action, and "IGF-independent" growth inhibitory or apoptotic effects of IGFBP-3 have been attributed to a variety of mechanisms, including its interaction with nuclear hormone receptors such as retinoid X receptor $[14,15]$ and the vitamin $\mathrm{D}$ receptor [16], TGF $\beta /$ SMAD signaling pathways $[17,18]$, and upregulation of apoptotic effectors [19].

By contrast with these inhibitory and apoptotic effects of IGFBP-3, however, it appears that in some tissues IGFBP-3 functions as a tumor promoter as it is associated with poor patient outcomes. Overexpression of IGFBP-3 has been shown in renal clear cell carcinoma [20] and head and neck squamous cancers [21], and expression is higher in primary tumor than adjacent normal tissue or benign disease tissue in pancreatic ductal adenocarcinoma [22] and oesophageal cancer [23]. There is also evidence of IGFBP-3 being associated with metastatic disease, with IGFBP-3 expression elevated in metastatic tissue compared with primary tumor in melanoma [24], and higher in metastatic than nonmetastatic tumors in pancreatic endocrine neoplasms [25]. However, perhaps the earliest and best-documented association of IGFBP-3 with poor patient outcome is in breast cancer.

\section{IGFBP-3 Is Highly Expressed in Aggressive Breast Cancer}

Early studies investigating the expression of IGFBP-3 in breast cancer cell lines revealed a negative correlation between expression of estrogen receptor (ER) and IGFBP-3 $[26,27]$. This is also seen in breast tumor tissue where many, though not all, studies have shown that expression of IGFBP$3 \mathrm{mRNA}$ and protein is higher in ER-negative tumors compared to ER-positive tumors [28-31]. The clinical significance of these findings was underscored by two independent groups showing that high expression of IGFBP-3 in breast tumor tissue is associated with markers of aggressiveness and poor prognosis, including ER- and progesterone receptor- (PR-) negativity, high S-phase fraction, and aneuploidy [32, 33]. Other studies showed that while there was no significant association of high tissue IGFBP-3 protein levels with breast cancer recurrence, long-term survival was reduced [34, 35].

Both cell culture and xenograft tumor models have shown that overexpression of IGFBP-3 can indeed result in enhanced growth of breast cancer cells. T47D, an ERpositive breast cancer cell line that normally expresses low IGFBP-3, was initially growth-inhibited in vitro when IGFBP3 was expressed ectopically but eventually developed resistance to its inhibitory effects and grew faster than vectortransfected cells [36]. This was reiterated in vivo using IGFBP3-expressing T47D cells to establish tumors in nude mice [37], where it was found that IGFBP-3-expressing T47D tumors grew faster and larger compared to those that did not express the protein.

\section{Mechanisms Underlying IGFBP-3's Growth-Stimulatory Actions}

It seems counterintuitive that IGFBP-3, a protein that has been shown in numerous breast cancer cell studies to be growth inhibitory and proapoptotic, is associated with aggressive forms of breast cancer. However, growth-stimulatory effects of IGFBP-3 have been documented in many cell types and contexts, and a variety of mechanisms, both IGF-dependent and -independent, have been described as underlying this bioactivity. Studies in fibroblasts and mammary epithelial cells indicated that IGFBP-3 can potentiate the actions of IGFs [38-40], possibly through modulation of IGF1R activation and AKT signaling pathways [39, 40]. A "switch" in the actions of IGFBP-3 from apoptotic to antiapoptotic was shown to be dependent on the presence of matrix components, with exogenous IGFBP-3 promoting breast cancer cell survival in the presence of fibronectin, but accentuating apoptosis triggered by ceramide in the absence of fibronectin [41]. Similarly, dual effects of IGFBP-3 as both pro- and antiapoptotic molecule have been reported in human umbilical vein endothelial cells (HUVEC), with IGFBP-3 potentiating apoptosis in the presence of doxorubicin, but promoting cell survival in its absence [42]. This was shown to correlate with IGFBP-3 differentially regulating proapoptotic ceramide production by the HUVECs, with IGFBP-3 stimulating ceramide production in the presence of doxorubicin, but reducing it in the absence of doxorubicin [42].

Investigation into possible mechanisms underlying the development of resistance to IGFBP-3's growth inhibitory effects in breast cells and pathways involved in its tumorigenic bioactivity revealed that phenotypically normal MCF-10A breast epithelial cells are growth-inhibited by exogenous IGFBP-3 but become refractory to its inhibitory effects when cells express HRas, an oncogenic form of the Ras protein which is constitutively active [43]. Hs578T breast cancer cells, which also express HRas, were similarly resistant to the inhibitory effects of IGFBP-3 but were resensitized to it in the presence of PD98059, an inhibitor of p44/42MAPK [43].

Although activating Ras mutations occur relatively rarely $(<5 \%)$ in breast cancer, aberrant activation of Ras signaling pathways downstream of growth factor receptors is considered an important driver of the tumorigenic process. As noted above, IGFBP-3 can enhance the growth-promoting effects of IGFs, and this has also been shown for other growth factors that activate receptors upstream of Ras, such as EGF and 
TGF $\beta$ [38, 44-47]. In MCF-10A cells, preincubation with exogenous IGFBP-3 enhanced EGF-stimulated cell proliferation, and this was associated with increased EGFR and p44/42 MAPK activation [47]. As in HRas-expressing cells, inhibition of p44/42 MAPK restored IGFBP-3's inhibitory activity [47]. Similarly, in the IGFBP-3-transfected T47D cell model described above, the acquisition of growthstimulation associated with IGFBP-3 expression was accompanied by enhanced EGFR signaling, and pharmacological blockade of EGFR tyrosine kinase activity resensitized cells to inhibition by IGFBP-3 [37].

\section{Potentiation of EGFR Signaling by IGFBP-3 Is Mediated by Sphingosine Kinase Signaling}

Potentiation of EGF signaling by estrogen in breast cancer cells has been shown to involve transactivation of EGFR by receptors for sphingosine 1-phosphate (S1P), a bioactive phospholipid generated by the phosphorylation of sphingosine by sphingosine kinases 1 and 2 (SphK1 and SphK2) [48]. Sukocheva and coworkers showed in MCF-7 breast cancer cells that estradiol increased SphK1 activity and the formation of S1P, with subsequent binding of S1P to one of its receptors, $\mathrm{S}_{3}$, which in turn transactivated EGFR $[49,50]$. IGFBP-3 had been shown to stimulate SphK1 expression and activity in HUVECs [42], raising the possibility that IGFBP-3 might enhance EGFR phosphorylation and signaling in breast cells via upregulation of SphK and S1P, and transactivation of EGFR. Investigation of this in MCF-10A cells showed that SphK1 expression and activity were increased by IGFBP-3 and that silencing of SphK1 expression blocked IGFBP-3's enhancement of ligand-stimulated EGFR phosphorylation [51]. The underlying mechanism involved transactivation of EGFR by $\mathrm{S}_{1} \mathrm{P}_{1}$ or $\mathrm{S}_{\mathrm{P}} \mathrm{P}_{3}$ because pharmacological inhibition or siRNA-mediated silencing of either S1P receptor prevented the effects of IGFBP-3. IGF1R was similarly subject to transactivation by S1P receptors in cells preincubated with IGFBP3 and stimulated with IGF-I [51]. Collectively, these data suggested that, in cells that express both IGFBP-3 and EGFR (or IGF1R), IGFBP-3 may promote growth via its potentiation of EGFR signaling secondary to increasing SphK1 activity and formation of S1P.

\section{Triple-Negative Breast Cancer: A Clinical Challenge}

The clinical significance of these findings in the context of breast cancer is that IGFBP-3 and EGFR are relatively highly expressed in some aggressive ER-negative and PRnegative tumors that lack amplification of HER2, which are now referred to as triple-negative breast cancers, or TNBC $[31,52,53]$. Because TNBC lack estrogen and progesterone receptors and HER2 is not amplified, these breast cancers are refractory to anticancer therapies that target these molecules. TNBC accounts for $15-20 \%$ of all breast cancer cases and often occurs in younger premenopausal women, including those of African ancestry, and is further characterized by high recurrence and high metastatic and mortality rates [53, 54]. Despite these tumors expressing EGFR, making them potentially susceptible to anti-EGFR therapies, studies have shown either no benefit or, in some instances, a worsening of clinical outcomes, associated with their use as single-line agents [55-57]. The default treatment for TNBC remains cytotoxic chemotherapy or radiation $[53,58]$ therapies that damage the cancer cell's DNA. The use of such therapies is associated with serious side effects [59], and the development of new treatments for TNBC that show increased efficacy but reduced toxicity is the subject of considerable interest among cancer biologists and oncologists.

\section{Targeting IGFBP-3 Signaling through Sphingosine Kinase in TNBC}

As alluded to above, TNBC typically express IGFBP-3 and EGFR, and Kaplan-Meier analysis of gene expression data [60] revealed that high expression of either IGFBP-3 or EGFR in ER-negative breast cancers is associated with shorter recurrence-free survival [61], and when both are highly expressed the hazard ratio is even higher (Figure 1). In light of the observed interactions between EGFR and IGFBP-3 signaling pathways, it was feasible that cotargeting these systems might be of potential benefit in the treatment of TNBC. While the most obvious way of inhibiting IGFBP-3 signaling would be to target the protein itself, its importance as an endocrine regulator of IGF metabolic activity makes such an approach unlikely to be clinically practical. An alternative approach in the setting of TNBC is to target IGFBP-3's effector pathway, the SphK system, in conjunction with EGFR inhibition.

An oncogenic role for SphK1 was first proposed more than a decade ago [62] and was supported by subsequent work showing the protective effect of SphK1 knockout against the development of tumors in a range of animal models [6365]. Interest in SphK1 as a therapeutic target in various cancers has grown enormously [66], and a number of inhibitors of SphK have been developed, some of which have reached clinical evaluation (as reviewed in [48]). The availability of such inhibitors made it feasible that if successful, a combinatorial approach of targeting this axis with EGFR could be rapidly implemented.

As in normal breast epithelial cells, endogenous and exogenous IGFBP-3 enhanced EGF-stimulated EGFR phosphorylation in four TNBC cell lines, and this was dependent on the expression and activity of SphK1 [31]. Under conditions where inhibition of EGFR or SphK1 alone had little effect on the growth of these cell lines in vitro, the combination of gefitinib and SKi-II (2-( $p$-hydroxyanilino)4 -( $p$-chlorophenyl)thiazole), an inhibitor of SphK1, essentially abolished cell proliferation [31]. Importantly, when the combination was tested in vivo using TNBC cells grown as xenograft tumors in nude mice, gefitinib in combination with SKi-II significantly attenuated tumor growth when used at concentrations that had no significant effect as single agents [31]. These promising proof-of-principle studies indicate that the approach of cotargeting EGFR and SphK1 has potential 

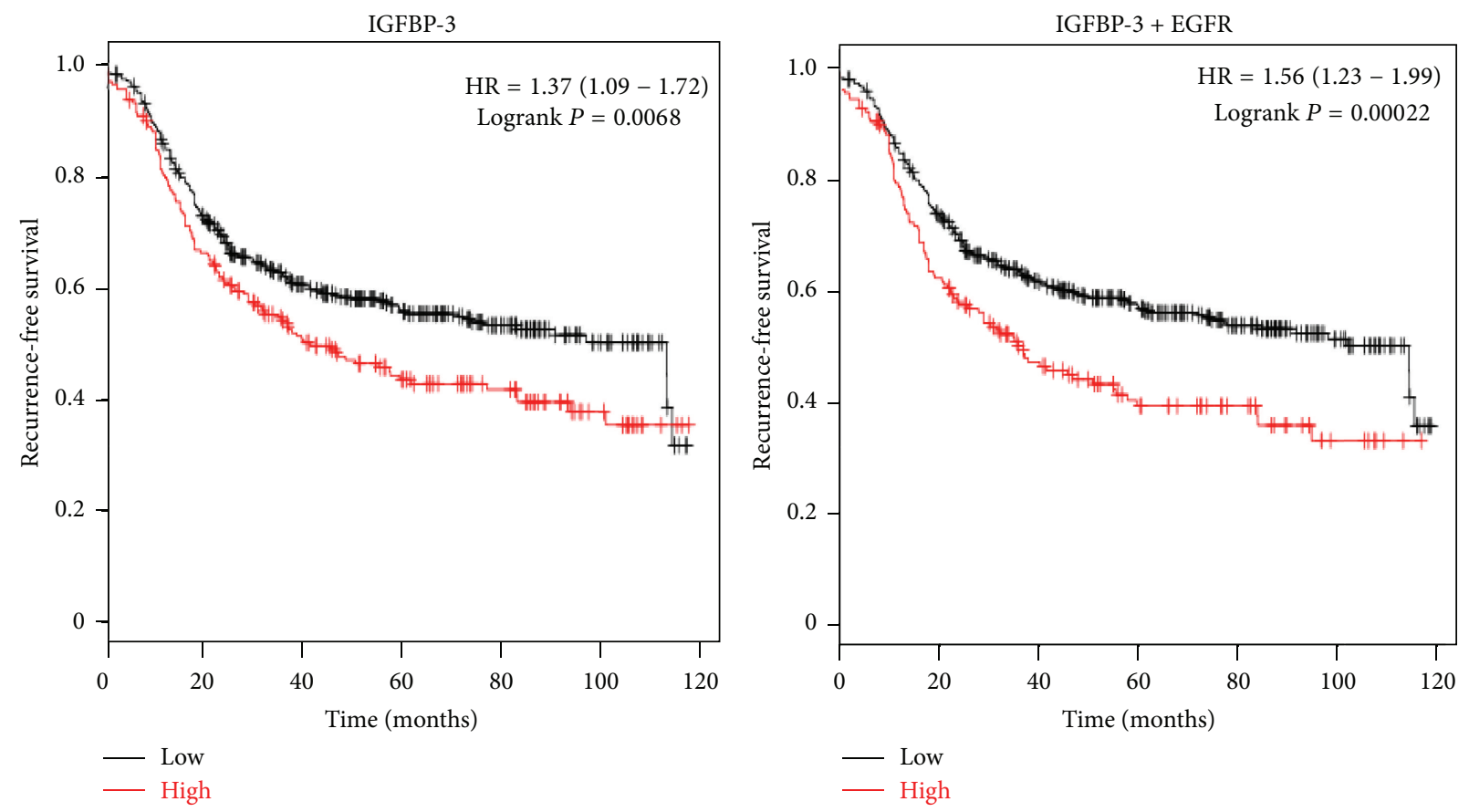

FIGURE 1: Kaplan-Meier analysis of gene expression data from 690 patients with ER-negative breast tumours shows that 10 -year recurrencefree survival is significantly worse if tissue IGFBP-3 is high (red) compared to low (black), and this difference is even greater if expression of both IGFBP3 and EGFR is high. HR: hazard ratio.

for the treatment of TNBC. In view of the known heterogeneity of TNBC, ongoing studies are now focussing on whether all subtypes of TNBC respond similarly to this combination treatment.

\section{IGFBP-3 and the DNA Damage Response: Can IGFBP-3 Alter Responsiveness to Chemo- and Radiotherapy?}

Activation of the tumor suppressor p53 in response to chemotherapy or radiotherapy plays an important part in the cytotoxic effects of these therapies [67]. Since the discovery of IGFBP3 as a p53-inducible gene in 1995 [68], studies in many cancer cell lines have demonstrated an increase in the expression of IGFBP-3 in response to treatment by chemotherapeutic drugs [69-71]. Because exogenous IGFBP3 has proapoptotic activity in many cell types, including breast cancer cells, either when used alone [72] or in combination with other apoptotic agents such as $\mathrm{C}_{2}$ ceramide [73], chemotherapy drugs [70], or radiation [19], the induction of IGFBP-3 in response to DNA-damaging therapies has been assumed to contribute to the cytotoxicity of these treatments. Consistent with this idea, IGFBP-3 is more highly expressed in certain chemo- or radiosensitive cancer cell lines than in matched resistant cell lines, as shown in cervical carcinoma and ovarian and lung cancer cells [74-76]. Similarly, when examined in patient NSCLC tumors, loss of IGFBP-3, mediated by promoter hypermethylation, has been found to be associated with decreased chemosensitivity [77].
However, the association of high IGFBP-3 expression with poor outcome in aggressive breast cancer [32, 35, 78] may, in addition to reflecting enhanced tumor growth as described above, reflect altered responsiveness to anticancer therapies. Thus in some breast cancers high IGFBP-3 expression might be associated with treatment resistance rather than sensitivity. Skog et al. [79] speculated that the relatively high expression of IGFBP-3 in ER-negative compared to ERpositive breast cancer cells and tumor tissue $[26,29]$ might contribute to enhanced DNA damage repair, which might in turn lead to relative resistance to DNA-damaging therapies. Although based on a very limited study, this speculation has turned out to have some experimental support in ER-negative breast cancer cell lines.

The authors have recently reported that IGFBP-3 has an integral role in the non-homologous end-joining (NHEJ) repair response to DNA double strand breaks (DSB) caused by the topoisomerase II poisons, etoposide, and doxorubicin [80]. Of the two major mechanisms of DSB repair (homologous recombination and NHEJ), NHEJ is relatively errorprone but can occur at any stage of the cell cycle, while homologous recombination is more faithful but is generally restricted to $S$ and $G 2$ phase $[81,82]$. NHEJ has been shown to involve EGFR which, in response to DNA-damaging agents, forms a nuclear complex with the catalytic subunit of one of the key kinases involved in NHEJ, DNA-dependent protein kinase (DNA-PKcs) [83]. In TNBC cell lines that have high IGFBP-3 expression, siRNA-mediated downregulation of IGFBP-3 was shown to inhibit the formation of this EGFRDNA-PKcs complex [80]. Further, IGFBP-3 itself formed DNA damage-dependent complexes with both EGFR and 
DNA-PKcs, suggesting the possibility of a nuclear ternary complex in the DSB repair process. IGFBP-3 downregulation also directly inhibited DNA DSB repair as measured in an in vitro NHEJ assay [80]. This suggests a previously unrecognized involvement of IGFBP-3 in chemotherapyinduced DNA DSB repair, which may in some circumstances lead to cancer cell recovery rather than apoptosis in response to cytotoxic drugs. IGFBP-3-dependent breast cancer cell chemoresistance, while contrary to studies in some other cancers showing IGFBP-3-dependent chemosensitivity, might in part explain the association between high IGFBP-3 (and EGFR) expression and poor patient outcomes in women with ER-negative breast cancer.

\section{Concluding Remarks}

It is clear that IGFBP-3 functions as a tumor promoter in some cancers, including TNBC. In TNBC it does so, at least in part, by potentiating growth-stimulatory signaling through the EGFR, and this requires SphK1. Understanding the mechanism involved in growth-stimulatory signaling by IGFBP-3 has led to the design of a combination treatment that cotargets both pathways involved and may therefore have improved efficacy not only in TNBC but in other cancers in which EGFR is highly expressed and IGFBP-3 functions as a tumor promoter. Further dissection of the molecular interactions and pathways by which IGFBP-3 may confer chemoresistance in TNBC also has the potential to identify other targets for the development of novel therapies to treat this aggressive disease.

\section{Conflict of Interests}

The authors declare that there is no conflict of interests regarding the publication of this paper.

\section{References}

[1] R. C. Baxter, "IGF binding proteins in cancer: mechanistic and clinical insights," Nature Reviews Cancer, vol. 14, no. 5, pp. 329341, 2014.

[2] B. E. Forbes, P. McCarthy, and R. S. Norton, "Insulin-like growth factor binding proteins: a structural perspective," Frontiers in Endocrinology, vol. 3, article 38, 2012.

[3] S. M. Firth and R. C. Baxter, "Cellular actions of the insulin-like growth factor binding proteins," Endocrine Reviews, vol. 23, no. 6, pp. 824-854, 2002.

[4] R. C. Baxter, "Circulating levels and molecular distribution of the acid-labile $(\alpha)$ subunit of the high molecular weight insulinlike growth factor-binding protein complex," Journal of Clinical Endocrinology and Metabolism, vol. 70, no. 5, pp. 1347-1353, 1990.

[5] J. Beattie, K. Phillips, J. H. Shand, M. Szymanowska, D. J. Flint, and G. J. Allan, "Molecular interactions in the insulin-like growth factor (IGF) axis: a surface plasmon resonance (SPR) based biosensor study," Molecular and Cellular Biochemistry, vol. 307, no. 1-2, pp. 221-236, 2008.

[6] H. B. Boldt and C. A. Conover, "Overexpression of pregnancyassociated plasma protein-a in ovarian cancer cells promotes tumor growth in vivo," Endocrinology, vol. 152, no. 4, pp. 14701478, 2011.

[7] M. Nakamura, S. Miyamoto, H. Maeda et al., "Matrix metalloproteinase-7 degrades all insulin-like growth factor binding proteins and facilitates insulin-like growth factor bioavailability," Biochemical and Biophysical Research Communications, vol. 333, no. 3, pp. 1011-1016, 2005.

[8] X. Yan, L. D. Payet, R. C. Baxter, and S. M. Firth, "Activity of human pregnancy insulin-like growth factor binding protein3: determination by reconstituting recombinant complexes," Endocrinology, vol. 150, no. 11, pp. 4968-4976, 2009.

[9] M. Guix, A. C. Faber, S. E. Wang et al., "Acquired resistance to EGFR tyrosine kinase inhibitors in cancer cells is mediated by loss of IGF-binding proteins," The Journal of Clinical Investigation, vol. 118, no. 7, pp. 2609-2619, 2008.

[10] J. L. Martin, J. A. Coverley, S. T. Pattison, and R. C. Baxter, "Insulin-like growth factor-binding protein-3 production by MCF-7 breast cancer cells: stimulation by retinoic acid and cyclic adenosine monophosphate and differential effects of estradiol," Endocrinology, vol. 136, no. 3, pp. 1219-1226, 1995.

[11] S. E. Pratt and M. N. Pollak, "Estrogen and antiestrogen modulation of MCF7 human breast cancer cell proliferation is associated with specific alterations in accumulation of insulinlike growth factor-binding proteins in conditioned media," Cancer Research, vol. 53, no. 21, pp. 5193-5198, 1993.

[12] H. Huynh, X. Yang, and M. Pollak, "Estradiol and antiestrogens regulate a growth inhibitory insulin-like growth factor binding protein 3 autocrine loop in human breast cancer cells," The Journal of Biological Chemistry, vol. 271, no. 2, pp. 1016-1021, 1996.

[13] F. Rozen, J. Zhang, and M. Pollak, "Antiproliferative action of tumor necrosis factor- $\alpha$ on MCF-7 breast cancer cells is associated with increased insulin-like growth factor binding protein-3 accumulation," International Journal of Oncology, vol. 13, no. 4, pp. 865-869, 1998.

[14] B. Liu, H.-Y. Lee, S. A. Weinzimer et al., "Direct functional interactions between insulin-like growth factor-binding protein-3 and retinoid $\mathrm{X}$ receptor- $\alpha$ regulate transcriptional signaling and apoptosis," The Journal of Biological Chemistry, vol. 275, no. 43, pp. 33607-33613, 2000.

[15] L. J. Schedlich, M. K. O’Han, G. M. Leong, and R. C. Baxter, "Insulin-like growth factor binding protein-3 prevents retinoid receptor heterodimerization: implications for retinoic acidsensitivity in human breast cancer cells," Biochemical and Biophysical Research Communications, vol. 314, no. 1, pp. 83-88, 2004.

[16] T. Ikezoe, S. Tanosaki, U. Krug et al., "Insulin-like growth factor binding protein-3 antagonizes the effects of retinoids in myeloid leukemia cells," Blood, vol. 104, no. 1, pp. 237-242, 2004.

[17] S. Fanayan, S. M. Firth, A. J. Butt, and R. C. Baxter, "Growth inhibition by insulin-like growth factor-binding protein-3 in T47D breast cancer cells requires transforming growth factor$\beta$ (TGF- $\beta$ ) and the type II TGF- $\beta$ receptor," The Journal of Biological Chemistry, vol. 275, no. 50, pp. 39146-39151, 2000.

[18] S. Fanayan, S. M. Firth, and R. C. Baxter, "Signaling through the Smad pathway by insulin-like growth factor-binding protein3 in breast cancer cells. Relationship to transforming growth factor- $\beta 1$ signaling," The Journal of Biological Chemistry, vol. 277, no. 9, pp. 7255-7261, 2002.

[19] A. J. Butt, S. M. Firth, M. A. King, and R. C. Baxter, "Insulin-like growth factor-binding protein-3 modulates expression of Bax and $\mathrm{Bcl}-2$ and potentiates p53-independent radiation-induced 
apoptosis in human breast cancer cells," The Journal of Biological Chemistry, vol. 275, no. 50, pp. 39174-39181, 2000.

[20] M. Takahashi, V. Papavero, J. Yuhas et al., "Altered expression of members of the IGF-axis in clear cell renal cell carcinoma," International Journal of Oncology, vol. 26, no. 4, pp. 923-931, 2005.

[21] A. Marimuthu, S. Chavan, G. Sathe et al., "Identification of head and neck squamous cell carcinoma biomarker candidates through proteomic analysis of cancer cell secretome," Biochimica et Biophysica Acta-Proteins and Proteomics, vol. 1834, no. 11, pp. 2308-2316, 2013.

[22] A. Xue, C. J. Scarlett, C. J. Jackson, B. J. Allen, and R. C. Smith, "Prognostic significance of growth factors and the urokinasetype plasminogen activator system in pancreatic ductal adenocarcinoma," Pancreas, vol. 36, no. 2, pp. 160-167, 2008.

[23] M. Takaoka, H. Harada, C. D. Andl et al., "Epidermal growth factor receptor regulates aberrant expression of insulin-like growth factor-binding protein 3," Cancer Research, vol. 64, no. 21, pp. 7711-7723, 2004.

[24] Y. Xi, G. Nakajima, T. Hamil, O. Fodstad, A. Riker, and J. $\mathrm{Ju}$, "Association of insulin-like growth factor binding protein3 expression with melanoma progression," Molecular Cancer Therapeutics, vol. 5, no. 12, pp. 3078-3084, 2006.

[25] D. E. Hansel, A. Rahman, M. House et al., "Met proto-oncogene and insulin-like growth factor binding protein 3 overexpression correlates with metastatic ability in well-differentiated pancreatic endocrine neoplasms," Clinical Cancer Research, vol. 10, no. 18, pp. 6152-6158, 2004.

[26] D. R. Clemmons, C. Camacho-Hubner, E. Coronado, and C. K. Osborne, "Insulin-like growth factor binding protein secretion by breast carcinoma cell lines: correlation with estrogen receptor status," Endocrinology, vol. 127, no. 6, pp. 2679-2686, 1990.

[27] J. A. Figueroa, J. G. Jackson, W. L. McGuire, R. F. Krywicki, and D. Yee, "Expression of insulin-like growth factor binding proteins in human breast cancer correlates with estrogen receptor status," Journal of Cellular Biochemistry, vol. 52, no. 2, pp. 196205, 1993.

[28] Z.-M. Shao, M. S. Sheikh, J. V. Ordonez et al., "IGFBP-3 gene expression and estrogen receptor status in human breast carcinoma," Cancer Research, vol. 52, no. 18, pp. 5100-5103, 1992.

[29] F. Pekonen, T. Nyman, V. Ilvesmaki, and S. Partanen, "Insulinlike growth factor binding proteins in human breast cancer tissue," Cancer Research, vol. 52, no. 19, pp. 5204-5207, 1992.

[30] J. L. Martin and R. C. Baxter, "Expression of insulin-like growth factor binding protein-2 by MCF-7 breast cancer cells is regulated through the phosphatidylinositol 3-kinase/AKT/ mammalian target of rapamycin pathway," Endocrinology, vol. 148, no. 5, pp. 2532-2541, 2007.

[31] J. L. Martin, H. C. De Silva, M. Z. Lin, C. D. Scott, and R. C. Baxter, "Inhibition of insulin-like growth factor-binding protein-3 signaling through sphingosine kinase-1 sensitizes triple-negative breast cancer cells to egf receptor Blockade," Molecular Cancer Therapeutics, vol. 13, no. 2, pp. 316-328, 2014.

[32] R. L. Rocha, S. G. Hilsenbeck, J. G. Jackson, A. V. Lee, J. A. Figueroa, and D. Yee, "Correlation of insulin-like growth factorbinding protein-3 messenger RNA with protein expression in primary breast cancer tissues: detection of higher levels in tumors with poor prognostic features," Journal of the National Cancer Institute, vol. 88, no. 9, pp. 601-606, 1996.

[33] H. Yu, M. A. Levesque, M. J. Khosravi, A. PapanastasiouDiamandi, G. M. Clark, and E. P. Diamandis, "Associations between insulin-like growth factors and their binding proteins and other prognostic indicators in breast cancer," British Journal of Cancer, vol. 74, no. 8, pp. 1242-1247, 1996.

[34] H. Yu, M. A. Levesque, M. J. Khosravi, A. PapanastasiouDiamandi, G. M. Clark, and E. P. Diamandis, "Insulin-like growth factor-binding protein-3 and breast cancer survival," International Journal of Cancer, vol. 79, no. 6, pp. 624-628, 1998.

[35] S. M. Sheen-Chen, H. Zhang, C. C. Huang, and R. P. Tang, "Insulin-like growth factor-binding protein-3 in breast cancer: analysis with tissue microarray," Anticancer Research, vol. 29, no. 4, pp. 1131-1135, 2009.

[36] S. M. Firth, S. Fanayan, D. Benn, and R. C. Baxter, "Development of resistance to insulin-like growth factor binding protein3 in transfected T47D breast cancer cells," Biochemical and Biophysical Research Communications, vol. 246, no. 2, pp. 325329, 1998.

[37] A. J. Butt, J. L. Martin, K. A. Dickson, F. McDougall, S. M. Firth, and R. C. Baxter, "Insulin-like growth factor binding protein-3 expression is associated with growth stimulation of T47D human breast cancer cells: the role of altered epidermal growth factor signaling," Journal of Clinical Endocrinology and Metabolism, vol. 89, no. 4, pp. 1950-1956, 2004.

[38] J. S. M. de Mellow and R. C. Baxter, "Growth hormonedependent insulin-like growth factor (IGF) binding protein both inhibits and potentiates IGF-I-stimulated DNA synthesis in human skin fibroblasts," Biochemical and Biophysical Research Communications, vol. 156, no. 1, pp. 199-204, 1988.

[39] C. A. Conover, "Potentiation of insulin-like growth factor (IGF) action by IGF-binding protein-3: studies of underlying mechanism," Endocrinology, vol. 130, no. 6, pp. 3191-3199, 1992.

[40] C. J. Grill and W. S. Cohick, "Insulin-like growth factor binding protein-3 mediates IGF-I action in a bovine mammary epithelial cell line independent of an IGF interaction," Journal of Cellular Physiology, vol. 183, pp. 273-283, 2000.

[41] C. McCaig, C. M. Perks, and J. M. P. Holly, "Intrinsic actions of IGFBP-3 and IGFBP-5 on Hs578T breast cancer epithelial cells: inhibition or accentuation of attachment and survival is dependent upon the presence of fibronectin," Journal of Cell Science, vol. 115, no. 22, pp. 4293-4303, 2002.

[42] R. Granata, L. Trovato, G. Garbarino et al., "Dual effects of IGFBP-3 on endothelial cell apoptosis and survival: involvement of the sphingolipid signaling pathways," The FASEB Journal, vol. 18, no. 12, pp. 1456-1458, 2004.

[43] J. L. Martin and R. C. Baxter, "Oncogenic ras causes resistance to the growth inhibitor insulin-like growth factor binding protein3 (IGFBP-3) in breast cancer cells," The Journal of Biological Chemistry, vol. 274, no. 23, pp. 16407-16411, 1999.

[44] C. A. Conover, "Glycosylation of insulin-like growth factor binding protein-3 (IGFBP-3) is not required for potentiation of IGF-I action: evidence for processing of cell-bound IGFBP-3," Endocrinology, vol. 129, no. 6, pp. 3259-3268, 1991.

[45] J.-C. Chen, Z.-M. Shao, M. S. Sheikh et al., "Insulin-like growth factor-binding protein enhancement of insulin-like growth factor-I (IGF-I)-mediated DNA synthesis and IGF-I binding in a human breast carcinoma cell line," Journal of Cellular Physiology, vol. 158, no. 1, pp. 69-78, 1994.

[46] P. Cohen, R. Rajah, J. Rosenbloom, and D. J. Herrick, "IGFBP-3 mediates TGF- $\beta 1$-induced cell growth in human airway smooth muscle cells," The American Journal of Physiology: Lung Cellular and Molecular Physiology, vol. 278, no. 3, pp. L545-L551, 2000.

[47] J. L. Martin, S. M. Weenink, and R. C. Baxter, "Insulin-like growth factor-binding protein-3 potentiates epidermal growth 
factor action in MCF-10A mammary epithelial cells. Involvement of p44/42 and p38 mitogen-activated protein kinases," Journal of Biological Chemistry, vol. 278, no. 5, pp. 2969-2976, 2003.

[48] H. Alshaker, L. Sauer, D. Monteil et al., "Therapeutic potential of targeting SK1 in human cancers," Advances in Cancer Research, vol. 117, pp. 143-200, 2013.

[49] O. A. Sukocheva, L. Wang, N. Albanese, S. M. Pitson, M. A. Vadas, and P. Xia, "Sphingosine kinase transmits estrogen signaling in human breast cancer cells," Molecular Endocrinology, vol. 17, no. 10, pp. 2002-2012, 2003.

[50] O. Sukocheva, C. Wadham, A. Holmes et al., "Estrogen transactivates EGFR via the sphingosine 1-phosphate receptor Edg3: the role of sphingosine kinase-1," The Journal of Cell Biology, vol. 173, no. 2, pp. 301-310, 2006.

[51] J. L. Martin, M. Z. Lin, E. M. McGowan, and R. C. Baxter, "Potentiation of growth factor signaling by insulin-like growth factor-binding protein-3 in breast epithelial cells requires sphingosine kinase activity," The Journal of Biological Chemistry, vol. 284, no. 38, pp. 25542-25552, 2009.

[52] S. Kobayashi, "Basal-like subtype of breast cancer: a review of its unique characteristics and their clinical significance," Breast Cancer, vol. 15, no. 2, pp. 153-158, 2008.

[53] I. A. Mayer, V. G. Abramson, B. D. Lehmann, and J. A. Pietenpol, "New strategies for triple-negative breast cancer-deciphering the heterogeneity," Clinical Cancer Research, vol. 20, no. 4, pp. 782-790, 2014.

[54] P. Boyle, "Triple-negative breast cancer: epidemiological considerations and recommendations," Annals of Oncology, vol. 23, no. 6, Article ID mds187, pp. vi7-vi12, 2012.

[55] M. F. Press, R. S. Finn, D. Cameron et al., "HER-2 gene amplification, HER-2 and epidermal growth factor receptor mRNA and protein expression, and lapatinib efficacy in women with metastatic breast cancer," Clinical Cancer Research, vol. 14, no. 23, pp. 7861-7870, 2008.

[56] R. S. Finn, M. F. Press, J. Dering et al., "Estrogen receptor, progesterone receptor, human epidermal growth factor receptor 2 (HER2), and epidermal growth factor receptor expression and benefit from lapatinib in a randomized trial of paclitaxel with lapatinib or placebo as first-line treatment in HER2-negative or unknown metastatic breast cancer," Journal of Clinical Oncology, vol. 27, no. 24, pp. 3908-3915, 2009.

[57] T.-C. Hsia, C.-Y. Tu, Y.-J. Chen et al., "Lapatinib-mediated cyclooxygenase-2 expression via epidermal growth factor receptor/HuR interaction enhances the aggressiveness of triplenegative breast cancer cells," Molecular Pharmacology, vol. 83, no. 4, pp. 857-869, 2013.

[58] C. L. Griffiths and J. L. Olin, "Triple negative breast cancer: a brief review of its characteristics and treatment options," Journal of Pharmacy Practice, vol. 25, no. 3, pp. 319-323, 2012.

[59] Y. Chen, P. Jungsuwadee, M. Vore, D. A. Butterfield, and D. K. St. Clair, "Collateral damage in cancer chemotherapy: oxidative stress in nontargeted tissues," Molecular Interventions, vol. 7, no. 3, pp. 147-156, 2007.

[60] B. Gyorffy, A. Lanczky, A. C. Eklund et al., "An online survival analysis tool to rapidly assess the effect of 22,277 genes on breast cancer prognosis using microarray data of 1,809 patients," Breast Cancer Research and Treatment, vol. 123, no. 3, pp. 725-731, 2010.

[61] R. C. Baxter, "Insulin-like growth factor binding protein3 (IGFBP-3): novel ligands mediate unexpected functions," Journal of Cell Communication and Signaling, vol. 7, no. 3, pp. 179-189, 2013.
[62] P. Xia, J. R. Gamble, L. Wang et al., "An oncogenic role of sphingosine kinase," Current Biology, vol. 10, no. 23, pp. 15271530, 2000.

[63] M. Kohno, M. Momoi, M. L. Oo et al., "Intracellular role for sphingosine kinase 1 in intestinal adenoma cell proliferation," Molecular and Cellular Biology, vol. 26, no. 19, pp. 7211-7223, 2006.

[64] T. Kawamori, T. Kaneshiro, M. Okumura et al., "Role for sphingosine kinase 1 in colon carcinogenesis," The FASEB Journal, vol. 23, no. 2, pp. 405-414, 2009.

[65] L. A. Heffernan-Stroud, K. L. Helke, R. W. Jenkins, A.-M. de Costa, Y. A. Hannun, and L. M. Obeid, "Defining a role for sphingosine kinase 1 in p53-dependent tumors," Oncogene, vol. 31, no. 9, pp. 1166-1175, 2012.

[66] L. A. Heffernan-Stroud and L. M. Obeid, "Sphingosine kinase 1 in cancer," Advances in Cancer Research, vol. 117, pp. 201-235, 2013.

[67] E. A. Bassett, W. Wang, F. Rastinejad, and W. S. El-Deiry, "Structural and functional basis for therapeutic modulation of p53 signaling," Clinical Cancer Research, vol. 14, no. 20, pp. 6376-6386, 2008.

[68] L. Buckbinder, R. Talbott, S. Velasco-Miguel et al., "Induction of the growth inhibitor IGF-binding protein 3 by p53," Nature, vol. 377, no. 6550, pp. 646-649, 1995.

[69] M. Giuliano, M. Lauricella, E. Vassallo, M. Carabillò, R. Vento, and G. Tesoriere, "Induction of apoptosis in human retinoblastoma cells by topoisomerase inhibitors," Investigative Ophthalmology \& Visual Science, vol. 39, no. 8, pp. 1300-1311, 1998.

[70] C. A. Fowler, C. M. Perks, P. V. Newcomb, P. B. Savage, J. R. Farndon, and J. M. Holly, "Insulin-like growth factor binding protein-3 (IGFBP-3) potentiates paclitaxel-induced apoptosis in human breast cancer cells," International Journal of Cancer, vol. 88, no. 3, pp. 448-453, 2000.

[71] R. Kawabata, S. Oie, M. Takahashi, H. Kanayama, T. Oka, and K. Itoh, "Up-regulation of insulin-like growth factor-binding protein 3 by 5 -fluorouracil ( $5-\mathrm{FU})$ leads to the potent antiproliferative effect of androgen deprivation therapy combined with 5-FU in human prostate cancer cell lines," International Journal of Oncology, vol. 38, no. 6, pp. 1489-1500, 2011.

[72] T. Nickerson, H. Huynh, and M. Pollak, "Insulin-like growth factor binding protein-3 induces apoptosis in MCF7 breast cancer cells," Biochemical and Biophysical Research Communications, vol. 237, pp. 690-693, 1997.

[73] Z. P. Gill, C. M. Perks, P. V. Newcomb, and J. M. P. Holly, "Insulin-like growth factor-binding protein (IGFBP-3) predisposes breast cancer cells to programmed cell death in a nonIGF-dependent manner," The Journal of Biological Chemistry, vol. 272, no. 41, pp. 25602-25607, 1997.

[74] M. P. Achary, W. Jaggernauth, E. Gross, A. Alfieri, H. P. Klinger, and B. Vikram, "Cell lines from the same cervical carcinoma but with different radiosensitivities exhibit different cDNA microarray patterns of gene expression," Cytogenetics and Cell Genetics, vol. 91, no. 1-4, pp. 39-43, 2000.

[75] T. Goto, M. Takano, M. Sakamoto et al., "Gene expression profiles with cDNA microarray reveal RhoGDI as a predictive marker for paclitaxel resistance in ovarian cancers," Oncology Reports, vol. 15, no. 5, pp. 1265-1271, 2006.

[76] Y. Sun, S. Zheng, A. Torossian et al., "Role of insulin-like growth factor-1 signaling pathway in cisplatin-resistant lung cancer cells," International Journal of Radiation Oncology, Biology, Physics, vol. 82, no. 3, pp. e563-e572, 2012. 
[77] I. I. de Caceres, M. Cortes-Sempere, C. Moratilla et al., "IGFBP3 hypermethylation-derived deficiency mediates cisplatin resistance in non-small-cell lung cancer," Oncogene, vol. 29, no. 11, pp. 1681-1690, 2010.

[78] S. B. Vestey, C. M. Perks, C. Sen, C. J. Calder, J. M. P. Holly, and Z. E. Winters, "Immunohistochemical expression of insulin-like growth factor binding protein-3 in invasive breast cancers and ductal carcinoma in situ: implications for clinicopathology and patient outcome," Breast Cancer Research, vol. 7, no. 1, pp. R119R129, 2005.

[79] S. Skog, Q. He, R. Khoshnoud, T. Fornander, and L.-E. Rutqvist, "Genes related to growth regulation, DNA repair and apoptosis in an oestrogen receptor-negative (MDA-231) versus an oestrogen receptor-positive (MCF-7) breast tumour cell line," Tumor Biology, vol. 25, no. 1-2, pp. 41-47, 2004.

[80] M. Z. Lin, K. A. Marzec, J. L. Martin, and R. C. Baxter, "The role of insulin-like growth factor binding protein-3 in the breast cancer cell response to DNA-damaging agents," Oncogene, vol. 33, no. 1, pp. 85-96, 2014.

[81] S. P. Jackson and J. Bartek, "The DNA-damage response in human biology and disease," Nature, vol. 461, no. 7267, pp. 10711078, 2009.

[82] I. Brandsma and D. C. Gent, "Pathway choice in DNA double strand break repair: observations of a balancing act," Genome Integrity, vol. 3, article 9, 2012.

[83] D. J. Chen and C. S. Nirodi, "The epidermal growth factor receptor: a role in repair of radiation-induced DNA damage," Clinical Cancer Research, vol. 13, no. 22, pp. 6555-6560, 2007. 


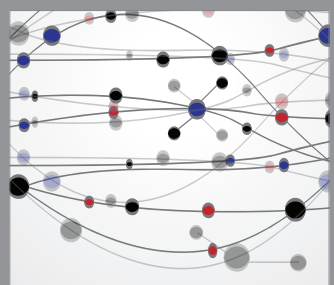

The Scientific World Journal
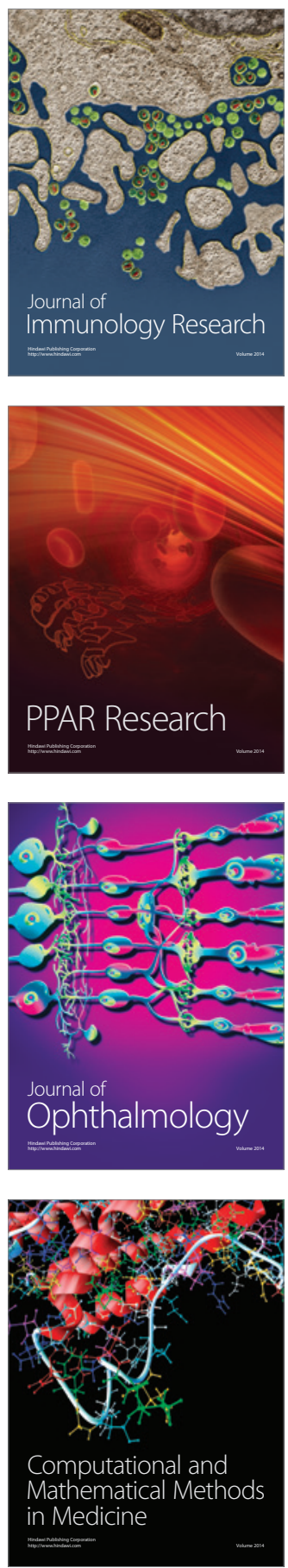

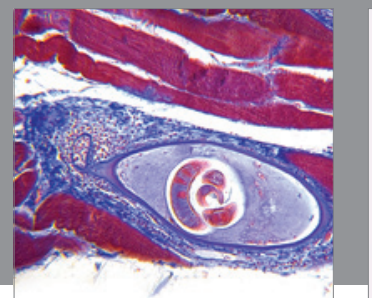

Gastroenterology

Research and Practice
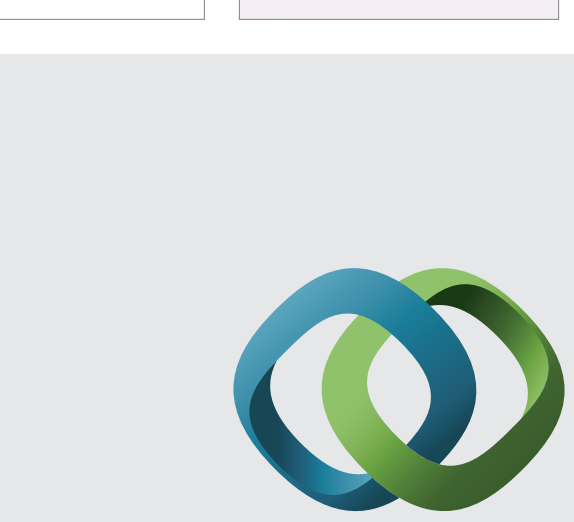

\section{Hindawi}

Submit your manuscripts at

http://www.hindawi.com
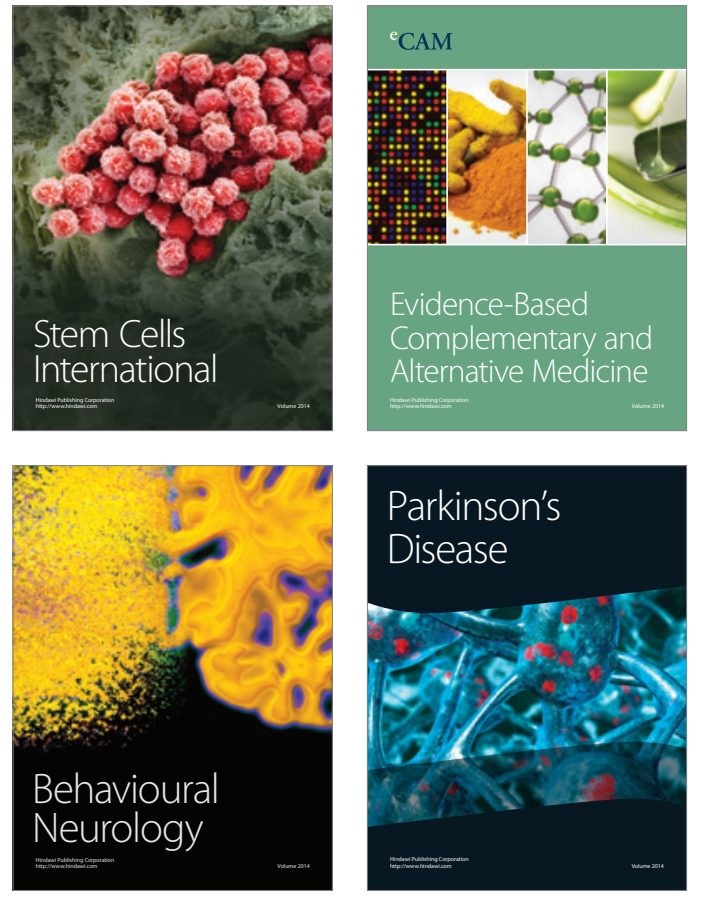
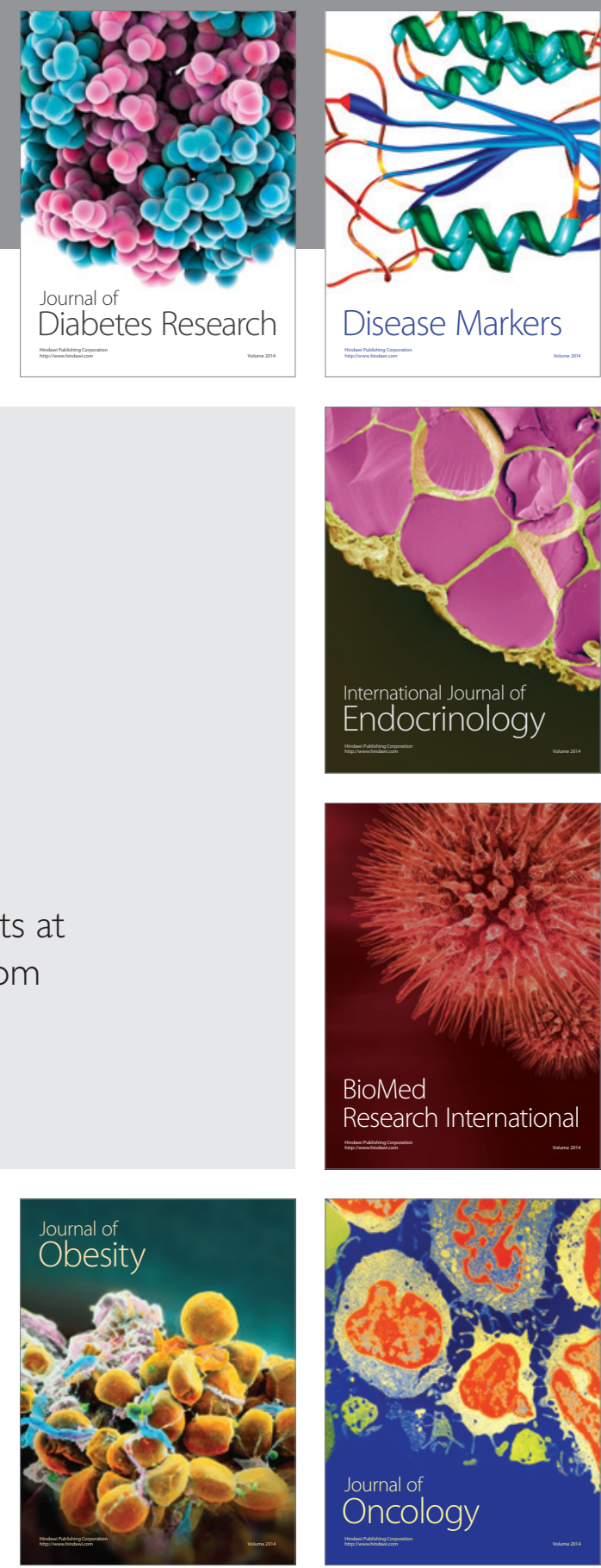

Disease Markers
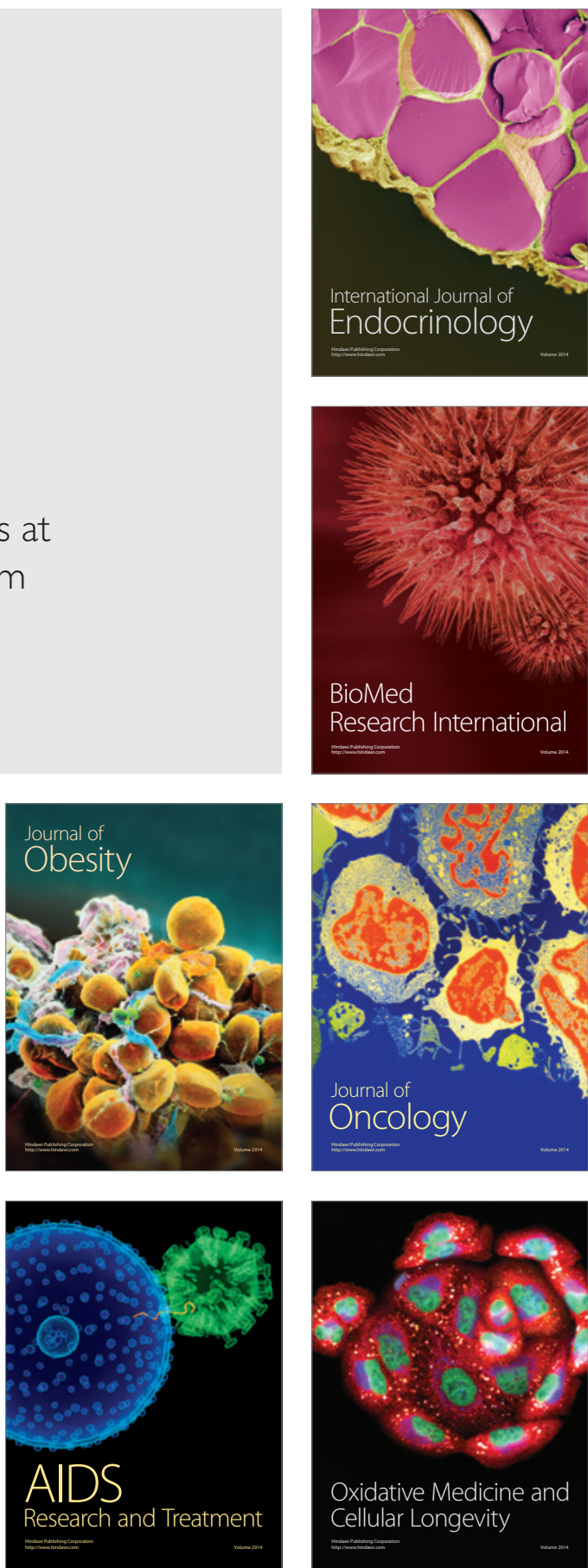